\title{
UCRL-TR-217228
}

LAWRENCE LIVERMORE N A TIO NAL LABORATORY
Addition of Tropospheric Chemistry and Aerosols to the NCAR Community Climate System Model

P. Cameron-Smith, J.-F. Lamarque, P. Connell, C. Chuang, D. Rotman, J. Taylor

November 21, 2005 
This document was prepared as an account of work sponsored by an agency of the United States Government. Neither the United States Government nor the University of California nor any of their employees, makes any warranty, express or implied, or assumes any legal liability or responsibility for the accuracy, completeness, or usefulness of any information, apparatus, product, or process disclosed, or represents that its use would not infringe privately owned rights. Reference herein to any specific commercial product, process, or service by trade name, trademark, manufacturer, or otherwise, does not necessarily constitute or imply its endorsement, recommendation, or favoring by the United States Government or the University of California. The views and opinions of authors expressed herein do not necessarily state or reflect those of the United States Government or the University of California, and shall not be used for advertising or product endorsement purposes.

This work was performed under the auspices of the U.S. Department of Energy by University of California, Lawrence Livermore National Laboratory under Contract W-7405-Eng-48. 


\section{Addition of Tropospheric Chemistry and Aerosols to the NCAR Community Climate System Model}

Part of the SciDAC CCSM Consortium

Philip Cameron-Smith ${ }^{1}$, Jean-Francois Lamarque ${ }^{2}$, Peter Connell ${ }^{1}$, Cathy Chuang ${ }^{1}$, Doug Rotman ${ }^{1}$, John Taylor ${ }^{3,1,4}$

${ }^{1}$ Lawrence Livermore National Laboratory (LLNL)

${ }^{2}$ National Center for Atmospheric Research (NCAR)

${ }^{3}$ Argonne National Laboratory (ANL)

${ }^{4}$ Now at Montclair State University

Atmospheric chemistry and aerosols have several important roles in climate change. They affect the Earth's radiative balance directly: cooling the earth by scattering sunlight (aerosols) and warming the Earth by trapping the Earth's thermal radiation (methane, ozone, nitrous oxide, and CFCs are greenhouse gases). Atmospheric chemistry and aerosols also impact many other parts of the climate system: modifying cloud properties (aerosols can be cloud condensation nuclei), fertilizing the biosphere (nitrogen species and soil dust), and damaging the biosphere (acid rain and ozone damage).

In order to understand and quantify the effects of atmospheric chemistry and aerosols on the climate and the biosphere in the future, it is necessary to incorporate atmospheric chemistry and aerosols into state-of-the-art climate system models. We have taken several important strides down that path. Working with the latest NCAR Community Climate System Model (CCSM), we have incorporated a state-of-the-art atmospheric chemistry model to simulate tropospheric ozone. Ozone is not just a greenhouse gas, it damages biological systems including lungs, tires, and crops. Ozone chemistry is also central to the oxidizing power of the atmosphere, which destroys a lot of pollutants in the atmosphere (which is a good thing).

We have also implemented a fast chemical mechanism that has high fidelity with the full mechanism, for significantly reduced computational cost (to facilitate millennium scale simulations).
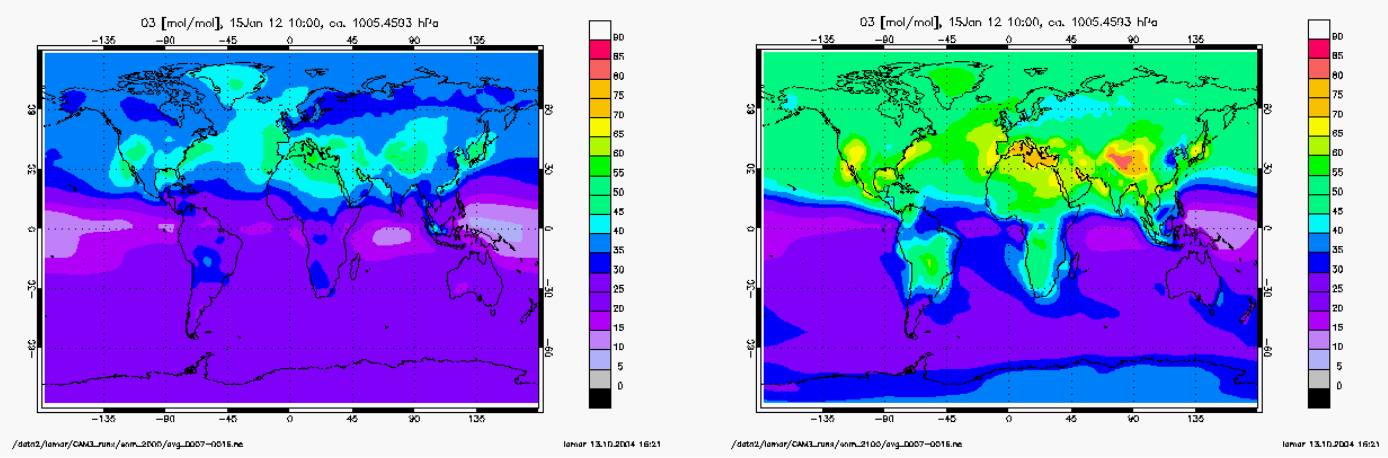

Figure 1: Ozone concentration (in ppb) at the surface in years 2000 (left) and 2100 (right) from the NCAR CCSM model with the full tropospheric chemistry we implemented. Note the increase 
in surface ozone concentration, which will lead to increased air-quality violations. The calculated ozone interacted radiatively with the climate model. This simulation used the A2 emission scenario from the Intergovernmental Panel on Climate Change (IPCC).

Sulfate aerosols have a strong effect on climate by reflecting sunlight and modifying cloud properties. So in order to simulate the sulfur cycle more fully in CCSM simulations, we have linked the formation of sulfate aerosols to the oxidizing power of the atmosphere calculated by the ozone mechanisms, and to di-methyl sulfide emissions from the ocean ecosystem in the model.
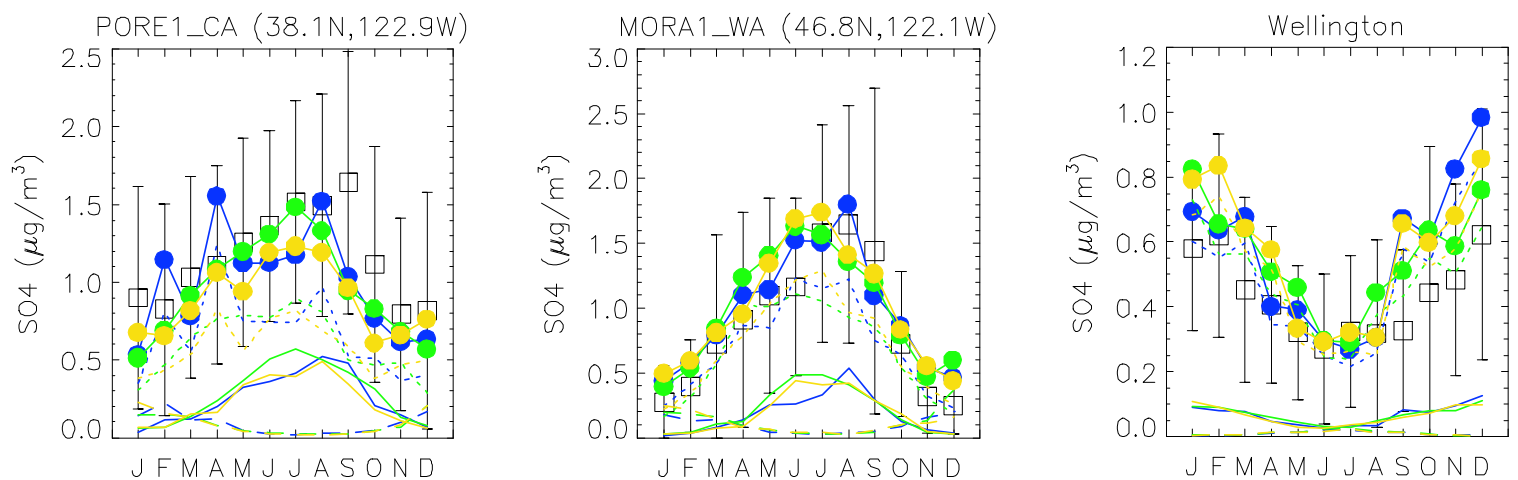

Figure 2: Comparison of monthly-mean surface sulfate concentrations from 3 years of simulation using the fast chemical mechanism (colored lines) against observations (box and whiskers) for sites in California, Washington, and New Zealand. The circles show total sulfate from the simulation, while the dotted, dashed, and dash-dotted lines show the separate sulfate contributions from sulfur dioxide oxidation by hydrogen peroxide, ozone, and hydroxyl radical, respectively.

Since the impact of sulfate aerosols depends on the relative abundance of other aerosols in the atmosphere, we also implemented interactive simulation of nitrate, sea-salt, black carbon, and both primary and secondary organic aerosols into CCSM (using assumed size distributions).
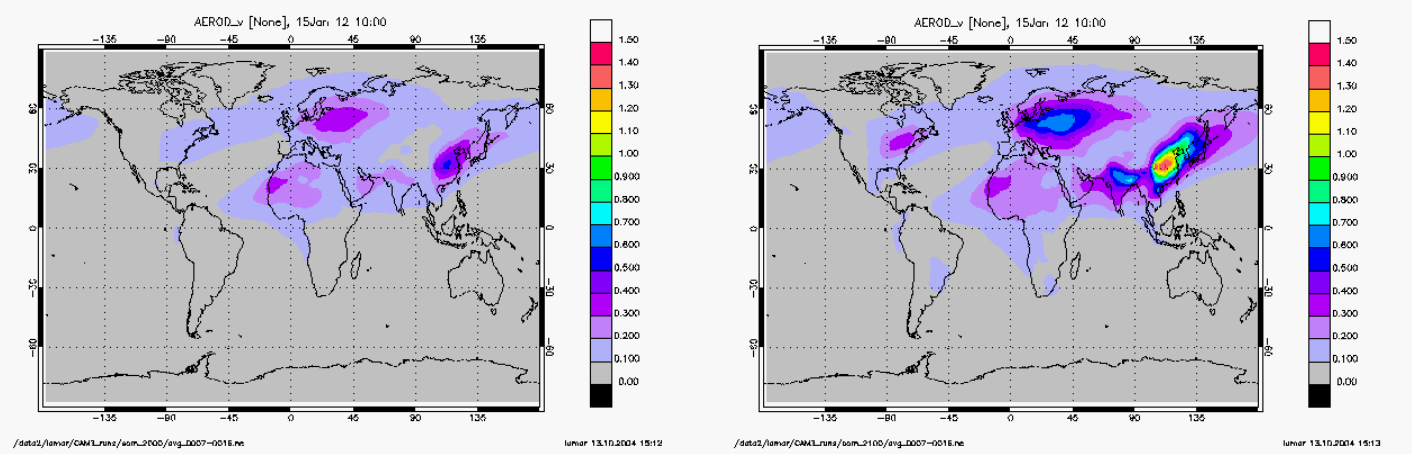

Figure 3: Total aerosol optical depth in years 2000 (left) and 2100 (right) from the NCAR CCSM model with the suite of aerosols we implemented. Note the significant increase in optical depth, which will produce a corresponding increase in radiative forcing. The calculated aerosols interacted radiatively with the climate model. This simulation used the A2 emission scenario from the Intergovernmental Panel on Climate Change (IPCC). 
These new capabilities are opening the door to studies of the role atmospheric chemistry and aerosols in climate change, and their impact on the biosphere, that were previously impossible. 